Research Article

\title{
Evaluation of Risk Factors for Predicting Mortality in Critically III Adult COVID- 19 Patients: A Retrospective Cohort Study
}

\author{
Geetanjali T Chilkoti', Vibhor Gupta', Sapna Jain ${ }^{3}$, Medha Mohta ${ }^{4}$, Rajeev Malhotra ${ }^{5}$, \\ Ashok Kumar Saxena ${ }^{6}$, Sanjana A Tiwari ${ }^{7}$, Chhavi S Sharma ${ }^{8}$ \\ ${ }^{1}$ Professor, ${ }^{2}$ Assistant Professor, ${ }^{3,7}$ Post Graduate, ${ }^{4}$ Director Professor, ${ }^{6} \mathrm{MD}$, Head of Department \& Professor, ${ }^{8} \mathrm{MD}$, Senior \\ Specialist, Department of Anaesthesia, UCMS \& GTB Hospital, Delhi, India. \\ ${ }^{5}$ Senior Research Scientist, Department of Statistics, Dr. BRA Irch, AIIMS, Delhi, India. \\ DOI: https://doi.org/10.24321/2349.7181.202110
}

\section{I $\quad \mathbf{N} \quad \mathbf{F} \quad \mathbf{O}$}

\section{Corresponding Author:}

Vibhor Gupta, Department of Anaesthesia, UCMS

\& GTB Hospital, Delhi, India.

E-mail Id:

vibhor817@gmail.com

Orcid Id:

https://orcid.org/0000-0002-1686-1353

How to cite this article:

Chilkoti GT, Gupta V, Jain S, Mohta M, Malhotra

$R$, Saxena AK, Tiwari SA, Sharma CS. Evaluation of Risk Factors for Predicting Mortality in Critically III Adult COVID-19 Patients: A Retrospective Cohort Study. J Adv Res Med. 2021;8(3):1-7.

Date of Submission: 2021-08-20

Date of Acceptance: 2021-09-25

\section{$\begin{array}{llllllll}\mathbf{A} & \mathbf{B} & \mathbf{S} & \mathbf{T} & \mathbf{R} & \mathbf{A} & \mathbf{C} & \mathbf{T}\end{array}$}

Background and Objective: Various risk factors have been evaluated to predict the mortality associated with COVID-19. We aim to explore and compare the clinical and laboratory risk factors with various outcomes of the disease between survivors and non-survivors amongst patients with moderate to severe COVID-19 disease.

Methods: All COVID-19 adult ( $\geq 18$ years old) ICU in-patients with a definite outcome i.e. either death or discharge were included. The demographic, clinical, laboratory, treatment, and outcome data were retrieved. To explore the association between factors, univariate and multivariate logistic regression were done.

Results: A total of 163 patients were included out of which eight patients were shifted to other hospitals. Finally, a total of 145 patients were included in the study. Out of 145, 47 patients didn't survive and 98 survived. A significant proportion (85\%) of non-survivors were current smokers and were observed to have COPD, $\mathrm{HT}$, and CAD as comorbidities when compared to the survivors. The qSOFA score, CRP, and TLC counts were included in the multivariable logistic regression with the former being the independent risk factor.

Interpretation and Conclusion: Our study highlighted that older age, higher SOFA score, increased levels of total leucocyte count, and C-Reactive protein were independent risk factors affecting the clinical outcome in moderate to severe COVID-19 patients; however, qSOFA was found to be an independent risk factor predictor.

Keywords: COVID-19, Comorbidity, Mortality, Risk Factors, Outcomes 


\section{Introduction}

In Wuhan, Hubei Province, China, a series of cases were reported of acute respiratory illness of unknown origin. ${ }^{1,2}$ It was caused by a virus which was named "severe acute respiratory syndrome coronavirus 2" (SARS-CoV-2). ${ }^{3}$ The World Health Organization officially named this disease as coronavirus disease 2019 (COVID-19) on February 11, 2020.

As far as the mortality is concerned, six (14.6\%) patients worsened in a short duration of time and eventually expired due to multiple organ failure in a cohort study of 41 patients with COVID-19 pneumonia from Wuhan. In another cohort study of patients with COVID-19 pneumonia, the overall mortality of $4.3 \%$ (six out of 138 ) was reported. ${ }^{4}$ Patient's clinical manifestations included fever with nonproductive cough, dyspnoea, myalgia, normal or decreased leucocyte counts, and evidence of pneumonia on chest radiograph imaging. Moreover, in severe cases, organ dysfunction and death were reported..$^{5,6}$ The results of single-arm metaanalysis by Li Q et al. showed that COVID-19 disease was seen more in the male gender. $60 \%$ of the total cases taken in the study were male. Also, it was found that the discharge rate of COVID-19 patients was $52 \%$, and a fatality rate of $5 \%$ was observed. $^{7}$

Various risk factors have been evaluated to predict the mortality associated with COVID-19 disease. Age $\geq 65$ years with pre-existing concurrent cardiovascular or cerebrovascular diseases, CD3+ CD8+ T-cells $\leq 75$ cells/ $\mu \mathrm{L}$ and cardiac troponin I $\geq 0.05 \mathrm{ng} / \mathrm{mL}$ were found to be the four risk factors in a prospective cohort study which could predict higher mortality in patients with COVID-19 pneumonia. ${ }^{4}$ Moreover, it was observed that there were increasing odds of in-hospital death of patients associated with older age (odds ratio 1.10), higher Sequential Organ Failure Assessment (SOFA) score $(p<0.0001)$, and d-dimer levels greater than $1.0 \mu \mathrm{g} / \mathrm{mL}(p=0.0033)$ on admission in a retrospective cohort study done in adult patients in two hospitals of Wuhan, China. In addition to this, it was observed that the median duration of viral shedding was 20.0 days in survivors, but continued until death in patients who expired. ${ }^{8}$

However, on literature search, we could not retrieve any study exploring the risk factors predicting the mortality in critically ill COVID-19 patients admitted in the ICU in the Indian sub-continent. Different strains of the COVID-19 virus are prevalent; therefore, it is desirable to have a study exploring their fatality and risk factors in different geographical regions.

Here, we have presented details of all patients with laboratory-confirmed COVID-19 admitted to the various critical care units in a tertiary care institute in the city of Delhi with a definite clinical outcome (death or discharge) from 01st August till 30th September 2020. We aimed to explore and compare the clinical and laboratory risk factors between the deceased and survivors amongst patients with moderate to severe COVID-19 disease admitted in the ICU, and describe the clinical course of symptoms, and laboratory findings at the time of admission in ICU along with various outcomes of the disease. The primary outcome was risk factors predicting mortality and the secondary outcomes were demographic characteristics, comorbidities, laboratory investigations, and SOFA scoring.

\section{Study Design: A Retrospective Study}

This study was undertaken following approval from the Institutional Ethics committee - Human Research. The written informed consent from each patient was waived since the data were collected retrospectively. The case sheets were retrieved by names but files were subsequently coded to maintain anonymity. All adult ( $\geq 18$ years old) inpatients admitted in the ICU in a tertiary care institute in the city of Delhi who were also diagnosed with COVID-19 according to the WHO interim guidance and had a definite outcome, i.e. either dead or discharged between 01 August 2020 till 30 September 2020 were included in the study. Paediatric, obstetric patients, and the ones who were shifted to other centres were excluded from the study. If the RTPCR report was found to be positive on nasopharyngeal swab then only cases were diagnosed as COVID-19 pneumonia. The patient's information which was collected prospectively included demographic data, laboratory tests, clinical manifestations, and outcomes. To double-check the collected data, it was reviewed independently by two researchers.

The data were extracted manually after retrieving the case files from the Medical Record Department. All data were checked twice by the aforementioned two physicians; however, a third researcher (MM) adjudicated any difference in interpretation between the two primary reviewers. Demographic characteristics like age, sex, duration of stay in the hospital and in the ICU, history of contact, travel history, status of smoking, and existence of various co-morbidities such as hypertension (HT), chronic obstructive pulmonary disease (COPD), diabetes mellitus (DM) etc. were recorded. Clinical manifestations, e.g. fever, cough, breathlessness, alteration in sense of smell and taste sensation, diarrhoea, and abdominal pain were recorded. The haemodynamic variables, i.e. systolic blood pressure, diastolic blood pressure, heart rate, respiratory rate, and oxygen saturation at the time of ICU admission were recorded from the case file. Laboratory procedures undertaken were also noted. The report of the repeat sample, if done, was also recorded. Routine blood examinations, e.g. complete blood count, total leucocyte count (TLC), coagulation profile, serum biochemical tests (including renal and liver function, 
creatine kinase, and electrolytes) were recorded from the case files. Chest radiographs and CT scans, if done, were also noted.

The disease severity of COVID-19 was defined according to the Clinical management protocol: COVID-19 by the Ministry of Health and Family Welfare, Govt. of India. Coagulopathy was defined as a 3-second extension of prothrombin time or 1.5 times increase in INR. Exposure history was defined as exposure to people with confirmed SARS-CoV-2 infection. ICU Scoring- Quick SOFA (qSOFA) scoring was done. Fever was defined as an axillary temperature of at least $37.3^{\circ} \mathrm{C}$. Patients were labelled to have sepsis or septic shock according to the Definition for Sepsis and Septic Shock given by the Third International Consensus in 2016. ${ }^{5}$ When there were clinical symptoms or signs of pneumonia or bacteremia and a positive culture of a new pathogen was obtained from lower respiratory tract specimens or blood samples after admission, then patients were diagnosed to have secondary infection. ${ }^{5}$ Ventilator-associated pneumonia was diagnosed in our patients according to the clinical practice guidelines given by Infectious Diseases Society of America and the American Thoracic Society. ${ }^{9}$ KDIGO clinical practice guidelines were used to diagnose acute kidney injury and Berlin Definition was used to diagnose acute respiratory distress syndrome (ARDS). ${ }^{10}$ If serum levels of cardiac biomarkers were above the 99th percentile upper reference limit, or if electrocardiography and echocardiography revealed new changes, then only acute cardiac injury was diagnosed. ${ }^{11}$ The various treatment patient had received was recorded retrospectively from their case files (Annexure-1). An evident cause of morbidity or mortality e.g. ARDS, heart failure, septic shock, coagulopathy or acute kidney injury was noted as perceived from the case file of the patient. The patient's outcome i.e. whether the patient was discharged or died, was recorded along with the number of days since the onset of illness, number of days on ventilator support etc. were recorded. The data from non-survivors such as the total number of days on ventilator, initial cardiac rhythm - shockable/ non-shockable, and whether the patient was on ionotropic support or not was also recorded from the case file.
Statistical analyses were done by using the SPSS software (version 20.0) IBM, Armonk, NY, USA). Descriptive variables were presented as mean, median (IQR), and proportion depending on the nature of data. Normally distributed continuous parameters were compared by unpaired t-test and skewed parameters were analysed by Mann-Whitney $U$ test. Qualitative parameters were analysed by Chi-square test and Fisher's exact test. The row which contained more than two missing variables were omitted from analysis and the row with one or two missing variables were replicated with the mean, median (IQR), or mode depending upon the nature of data. To explore the association between factors such as clinical characteristics and laboratory parameterswith the risk of death, univariate and multivariate logistic regression was used.

\section{Results}

A total of 163 patients were admitted in the various ICUs of the institute during the aforementioned period. Eight patients subsequently left against the medical advice and were shifted to other hospitals. Finally, a total of 145 patients with moderate to severe disease in the various ICUs were included in the study. Out of 145, 47 patients didn't survive. The demographic characteristics of 145 patients are included in Table 1. The mean age of survivors has been observed to be younger than non-survivors. Similarly, amongst non-survivors, there were more males (68\%). A significant proportion (85\%) of non-survivors were current smokers. A significant proportion of non-survivors were observed to have COPD, HT, and CAD as comorbidities when compared to survivors. The mean time from onset of illness to hospital admission was observed to be 11.0 (7.0-14.0) days. qSOFA score at the time of ICU admission was used for risk stratification and was significantly higher amongst non-survivors when compared to survivors [4.0(4.0-6.0) vs $1.0(1.0-2.0)]$.

The laboratory investigations and treatment given to the patients are shown in Table 2 . Serum creatinine $>133 \mu \mathrm{mol} / \mathrm{L}$ was observed to be higher amongst non-survivors. All nonsurvivors were observed to have CRP > 20 at the time of ICU admission (Table 2).

Table I.Demographic Characteristics of COVID- I 9 Patients

\begin{tabular}{|c|c|c|c|c|c|}
\hline \multicolumn{2}{|c|}{ Variables } & $\begin{array}{c}\text { Total } \\
(\mathbf{N}=\mathbf{1 4 5})\end{array}$ & $\begin{array}{c}\text { Non-survivors } \\
(\mathbf{N}=\mathbf{4 7})\end{array}$ & $\begin{array}{c}\text { Survivors } \\
(\mathbf{N}=\mathbf{9 8})\end{array}$ & P-Value \\
\hline \multirow{2}{*}{ Age } & $57.0(45.0-67.0)$ & $65.0(62.0-72.0)$ & $58.0(42.0-60.0)$ & $<0.001$ \\
\hline \multirow{2}{*}{ Gender } & Female & $40.6 \%(n=59)$ & $31.1 \%(n=15)$ & $44.8 \%(n=44)$ & - \\
\cline { 2 - 7 } & Male & $59.3 \%(n=86)$ & $68.0 \%(n=32)$ & $55.1 \%(n=54)$ & - \\
\hline \multicolumn{2}{|c|}{ Exposure history } & $48.9 \%(n=71)$ & $44.6 \%(n=21)$ & $51.0 \%(n=50)$ & - \\
\hline \multicolumn{2}{|c|}{ Current smoker } & $42.0 \%(n=61)$ & $85.1 \%(n=40)$ & $21.4 \%(n=21)$ & - \\
\hline \multirow{2}{*}{ Comorbodity } & COPD & $40 \%(n=58)$ & $68.0 \%(n=32)$ & $26.5 \%(n=26)$ & 0.0007 \\
\cline { 2 - 7 } & Diabetes mellitus & $58.6 \%(n=85)$ & $34.0 \%(n=50)$ & $35.7 \%(n=35)$ & 0.0008 \\
\hline
\end{tabular}




\begin{tabular}{|c|c|c|c|c|c|}
\hline \multirow{4}{*}{} & Hypertension & $31.0 \%(\mathrm{n}=45)$ & $21.0 \%(\mathrm{n}=31)$ & $14.2 \%(\mathrm{n}=14)$ & $<0.0001$ \\
\cline { 2 - 6 } & CKD & $1.37 \%(\mathrm{n}=2)$ & $0 \%$ & $2.01 \%(\mathrm{n}=2)$ & 0.43 \\
\cline { 2 - 6 } & CAD & $12.4 \%(\mathrm{n}=18)$ & $8.8 \%(\mathrm{n}=13)$ & $5.1 \%(\mathrm{n}=5)$ & $<0.0001$ \\
\cline { 2 - 6 } & Autoimmune disease & $2.0 \%(\mathrm{n}=3)$ & $0.6 \%(\mathrm{n}=1)$ & $2.0 \%(\mathrm{n}=2)$ & $<0.0001$ \\
\hline $\begin{array}{c}\text { Time from onset of illness to admission } \\
\text { (in days) }\end{array}$ & $11.0(7.0-14.0)$ & $10.5(8.0-15.0)$ & $11.0(8.0-14.0)$ & 0.54 \\
\hline \multirow{2}{*}{\begin{tabular}{c} 
Disease severity \\
\cline { 2 - 6 }
\end{tabular}} & $35 \%(\mathrm{n}=51)$ & $12 \%(\mathrm{n}=6)$ & $53 \%(\mathrm{n}=51)$ & - \\
\hline \multicolumn{2}{|c|}{ Moderate } & $30 \%(\mathrm{n}=44)$ & $80 \%(\mathrm{n}=38)$ & $9 \%(\mathrm{n}=6)$ & - \\
\hline
\end{tabular}

Table 2.Laboratory Investigations and Treatment

\begin{tabular}{|c|c|c|c|c|c|}
\hline \multicolumn{2}{|c|}{ Laboratory Investigations } & $\begin{array}{c}\text { Total } \\
(\mathrm{N}=145)\end{array}$ & $\begin{array}{l}\text { Non-survivors } \\
\quad(\mathrm{N}=47)\end{array}$ & $\begin{array}{l}\text { Survivors } \\
(N=98)\end{array}$ & P-Value \\
\hline \multicolumn{2}{|c|}{ Haemoglobin (g/dl) } & $12.6(11.6-15.1)$ & $12.7(11.9-13.8)$ & $12.7(12.0-14.1)$ & 0.3 \\
\hline \multicolumn{2}{|c|}{ Platelet count $\left(10^{4}\right.$ cells'/L) } & $20.6(15.3-29.0)$ & $16.95(11.0-22.8)$ & $23.1(16.1-27.4)$ & - \\
\hline \multirow{2}{*}{ Chest $\mathrm{X}$ ray $\mathrm{PA}$ view } & $\mathrm{B} / \mathrm{L}$ infiltrates & $84(68 \%)$ & $35(75 \%)$ & 49 (51\%) & 0.0064 \\
\hline & Consolidation & $110(76 \%)$ & $39(84 \%)$ & $71(73 \%)$ & 0.098 \\
\hline \multicolumn{2}{|c|}{ Serum creatinine (> 133 $\mu \mathrm{mol} / \mathrm{L})$} & $6 \%(n=9)$ & $9 \%(n=4)$ & $2 \%(n=2)$ & 0.050 \\
\hline \multicolumn{2}{|c|}{ Alanine transaminase (U/L) } & $24.0(17.0-41.0)$ & $38.0(21.0-49.0)$ & $25.0(13.0-36.0)$ & 0.005 \\
\hline \multicolumn{2}{|c|}{ Treatment } & n (\%) & n (\%) & n (\%) & P-Value \\
\hline \multicolumn{2}{|c|}{ Antibiotics } & $139(96)$ & $46(98)$ & $93(93)$ & 0.18 \\
\hline \multicolumn{2}{|c|}{ Antiviral treatment } & $44(30)$ & $16(31)$ & $28(30)$ & 0.81 \\
\hline \multicolumn{2}{|c|}{ Corticosteroids } & $138(95)$ & $46(98)$ & $92(93)$ & 0.15 \\
\hline \multicolumn{2}{|c|}{ LMW Heparin } & $139(96)$ & $46(98)$ & $93(93)$ & 0.16 \\
\hline \multicolumn{2}{|c|}{ Tocilizumab } & $3(2)$ & $3(6)$ & - & 0.0054 \\
\hline
\end{tabular}

Table 3.Outcomes amongst Both Survivors and Non-survivors

\begin{tabular}{|c|c|c|c|c|}
\hline Outcomes & $\begin{array}{c}\text { Total (N = 145) } \\
\mathbf{n}(\%)\end{array}$ & $\begin{array}{c}\text { Non-survivors (N = 47) } \\
\mathbf{n}(\%)\end{array}$ & $\begin{array}{c}\text { Survivors (N = 98) } \\
\mathbf{n}(\%)\end{array}$ & P-Value \\
\hline Sepsis & $87(60)$ & $47(100)$ & $40(41)$ & $<0.0001$ \\
\hline Respiratory failure & $80(55)$ & $47(100)$ & $33(34)$ & $<0.0001$ \\
\hline ARDS & $58(40)$ & $46(97)$ & $12(13)$ & $<0.0001$ \\
\hline Septic shock & $29(20)$ & $21(75)$ & $8(0)$ & $<0.0001$ \\
\hline Acute cardiac injury & $44(30)$ & $28(60)$ & $2(2)$ & $<0.0001$ \\
\hline AKI & $25(17)$ & $23(51)$ & $0(0)$ & $<0.0001$ \\
\hline Acidosis & $9(6)$ & $9(40)$ & $5(5)$ & $<0.0001$ \\
\hline Coagulopathy & $29(20)$ & $24(52)$ & & $<0.0001$ \\
\hline
\end{tabular}

Amongst the co-morbidities present during the course of stay, $100 \%$ of the non-survivors had sepsis and respiratory failure, followed by ARDS, sepsis, and AKI (Table 3).

The three factors qSOFA score (continuous), CRP $(>20, \leq 20)$, and TLC count $(>11, \leq 11)$ were included in the multivariable logistic regression (Table 4).The multivariable logistic regression revealed that amongst the aforementioned three factors, qSOFA was significantly associated with mortality. The significance of qSOFA score indicates that in its presence, there is no additional advantage of CRP and TLC in predicting mortality. 
Table 4.Multivariate Analysis

\begin{tabular}{|c|c|c|c|}
\hline Variable Name & B (SE) & Odds Ratio (95\% CI) & P-value \\
\hline qSOFA score (per unit increase) & $4.31(1.19)$ & $74.74[7.22$ to 773.33$]$ & $<0.01$ \\
\hline CRP $>20(\leq 20$ as reference) & $2.67(1.90)$ & $14.44[0.35$ to 590.43$]$ & 0.160 \\
\hline TLC count $>11$ ( $\leq 11$ as reference) & $1.83(1.71)$ & $6.23[0.22$ to 178.12$]$ & 0.285 \\
\hline
\end{tabular}

The model correctly classifies 96.6\% [99.0\% non-survivor, 91.3\% survivor], Cox-snell R-square 0.661

\section{Discussion}

In the present retrospective study on univariate analysis, three factors i.e. qSOFA score (continuous), CRP, and TLC counts were observed to be significantly higher amongst non-survivors and the multivariable logistic regression revealed that amongst the aforementioned three factors, only qSOFA was found to be significantly associated with mortality.

The clinical spectrum range is wide in cases of SARS-CoV-2 infection. Patients may have an asymptomatic infection or mild upper respiratory tract illness, and in severe viral pneumonia, respiratory failure may be observed and even death can occur. ${ }^{8}$ The early reports of SARS-CoV2-associated COVID-19 disease suggested that in SARSlike atypical pneumonia, 26 to $33 \%$ of patients required intensive care with mortality ranging from $4 \%-15 \% .12,13$

Our study showed higher mortality in the old age group with more preponderance in males. A prospective cohort study showed that age $\geq 65$ years was one of the risk factors predicting high mortality of COVID-19 pneumonia patients. ${ }^{4}$ Moreover, in a single-centre study of 144 hospitalised patients with confirmed COVID-19 in North India, severe disease was seen more amongst male patients. ${ }^{14}$

Various comorbidities are known to influence the disease severity and patient outcome in COVID-19. In the present study, the most common comorbidity was COPD, followed by $\mathrm{DM}, \mathrm{HT}$, and CAD. In one of the multicentric, retrospective cohort studies, non-survivors were more frequently having diabetes, hypertension, and CAD. ${ }^{8}$ Similar results were observed in a prospective study conducted on 179 COVID-19 patients. ${ }^{4}$ In some previous studies, hypertension was observed to be the most common associated comorbidity followed by DM. ${ }^{15,16}$ Similar to our observation, smoking was noted as a risk factor associated with severity of COVID-19 disease in many other studies as well. ${ }^{17,18}$

SOFA score has been observed to be a diagnostic marker for sepsis and septic shock, and also helps in assessing the state and degree of multi-organ dysfunction. ${ }^{19,20}$ There was a good correlation between SOFA score and mortality as revealed in our study in line with a retrospective cohort study done in Wuhan, China. ${ }^{8}$ In another study, SOFA score was one of the risk factors with poor prognosis in COVID-19 patients. ${ }^{21}$
Our study observed certain laboratory parameters which correlated significantly to mortality in these patients. We noted that patients with increased levels of TLC, C Reactive protein, and ALT had increased incidence of mortality. A preliminary study in India observed that $24 \mathrm{hr} \mathrm{ICU}$ mortality was $8.5 \%$, and non-survivors had higher TLC along with a higher absolute neutrophil count, prothrombin time and INR (international normalized ratio). ${ }^{13}$ Another study also stated that C-Reactive protein and total leucocyte count are strong predictors of mortality in COVID-19 patients. ${ }^{4,22}$

In concordance with our study, it was observed that alanine transaminase is also an associated risk factor with mortality among non-survivors in another research done in Wuhan, China. ${ }^{8}$ In the present study, sepsis and respiratory failure were the most frequently observed outcome, followed by ARDS, heart failure, and septic shock.

Some limitations were observed in our study. First, the study design which was retrospective was a limitation. Moreover, few laboratory tests like lactate dehydrogenase, and serum ferritin were not done in all patients. Also, the lack of effective antivirals and use of high-dose corticosteroids might have also contributed to the poor clinical outcomes in some patients. Also, the study followed patients during the in-hospital course only, therefore, follow up details of survivors could not be done. Last but not least, interpretation of our findings might be limited by the sample size.

\section{Conclusion}

To conclude, our study highlighted that older age, higher SOFA score, increased levels of total leucocyte count, and C-Reactive protein were independent risk factors affecting the clinical outcome in critically ill COVID-19 patients.

\section{Acknowledgement}

Authors acknowledge the contribution of all the faculty and residents of the relevant departments, Hospital Infection Control Committee, and all the healthcare providers of the institute.

\section{Funding: None}

\section{Conflict of Interest: None}

\section{References}

1. Li Q, Guan X, Wu P, Wang X, Zhou L, Tong Y, Ren R, Leung KS, Lau EH, Wong JY, Xing X, Xiang N, Wu Y, Li C, Chen 
Q, Li D, Liu T, Zhao J, Liu M, Tu W, Chen C, Jin L, Yang R, Wang Q, Zhou S, Wang R, Liu H, Luo Y, Liu Y, Shao G, Li H, Tao Z, Yang Y, Deng Z, Liu B, Ma Z, Zhang Y, Shi G, Lam TT, Wu JT, Gao GF, Cowling BJ, Yang B, Leung GM, Feng Z. Early transmission dynamics in Wuhan, China, of novel coronavirus-infected pneumonia. N Engl J Med. 2020;382:1199-207. [PubMed] [Google Scholar]

2. Zhu N, Zhang D, Wang W, Li X, Yang B, Song J, Zhao X, Huang B, Shi W, Lu R, Niu P, Zhan F, Ma X, Wang D, Xu W, Wu G, Gao GF, Tan W; China Novel Coronavirus Investigating and Research Team. A novel coronavirus from patients with pneumonia in China, 2019. N Engl J Med. 2020;382:727-33. [PubMed] [Google Scholar]

3. Lu R, Zhao X, Li J, Niu P, Yang B, Wu H, Wang W, Song $H$, Huang B, Zhu N, Bi Y, Ma X, Zhan F, Wang L, Hu T, Zhou H, Hu Z, Zhou W, Zhao L, Chen J, Meng Y, Wang J, Lin Y, Yuan J, Xie Z, Ma J, Liu WJ, Wang D, Xu W, Holmes EC, Gao GF, Wu G, Chen W, Shi W, Tan W. Genomic characterisation and epidemiology of 2019 novel coronavirus: implications for virus origins and receptor binding. Lancet. 2020;395:556-74. [PubMed] [Google Scholar]

4. Du RH, Liang LR, Yang CQ, Wang W, Cao TZ, Li M, Guo GY, Du J, Zheng CL, Zhu Q, Hu M, Li XY, Peng P, Shi HZ. Predictors of mortality for patients with COVID-19 pneumonia caused by SARS-CoV-2: a prospective cohort study. Eur Respir J. 2020;55(5):2000524. [PubMed] [Google Scholar]

5. Huang $C$, Wang $Y$, Li X, Ren L, Zhao J, Hu Y, Zhang L, Fan G, Xu J, Gu X, Cheng Z, Yu T, Xia J, Wei Y, Wu W, Xie X, Yin W, Li H, Liu M, Xiao Y, Gao H, Guo L, Xie J, Wang G, Jiang R, Gao Z, Jin Q, Wang J, Cao B. Clinical features of patients infected with 2019 novel coronavirus in Wuhan, China. Lancet. 2020;395:497-506. [PubMed] [Google Scholar]

6. Wang D, Hu B, Hu C, Zhu F, Liu X, Zhang J, Wang B, Xiang $\mathrm{H}$, Cheng Z, Xiong Y, Zhao Y, Li Y, Wang X, Peng Z. Clinical characteristics of 138 hospitalized patients with 2019 novel coronavirus-infected pneumonia in Wuhan, China. JAMA. 2020;323(11):1061-9. [PubMed] [Google Scholar]

7. Li LQ, Huang T, Wang YQ, Wang ZP, Liang Y, Huang TB, Zhang HY, Sun W, Wang Y. COVID-19 patients' clinical characteristics, discharge rate, and fatality rate of metaanalysis. J Med Virol. 2020;92(6):577-83. [PubMed] [Google Scholar]

8. Zhou F, Yu T, Du R, Fan G, Liu Y, Liu Z, Xiang J, Wang Y, Song B, Gu X, Guan L, Wei Y, Li H, Wu X, Xu J, Tu S, Zhang $Y$, Chen $\mathrm{H}, \mathrm{Cao} B$. Clinical course and risk factors for mortality of adult inpatients with COVID-19 in Wuhan, China: a retrospective cohort study. Lancet. 2020;395(10229):1054-62. [PubMed] [Google Scholar]

9. Kalil AC, Metersky ML, Klompas M, Muscedere J,
Sweeney DA, Palmer LB, Napolitano LM, O'Grady NP, Bartlett JG, Carratalà J, El Solh AA, Ewig S, Fey PD, File Jr TM, Restrepo MI, Roberts JA, Waterer GW, Cruse $\mathrm{P}$, Knight SL, Brozek JL. Management of adults with hospital-acquired and ventilator-associated pneumonia: 2016 clinical practice guidelines by the Infectious Diseases Society of America and the American Thoracic Society. Clin Infect Dis. 2016;63:e61-111. [PubMed] [Google Scholar]

10. Khwaja A. KDIGO clinical practice guidelines for acute kidney injury. Nephron Clin Pract. 2012;120:c179-84. [PubMed] [Google Scholar]

11. ARDS Definition Task Force; Ranieri VM, Rubenfeld GD, Thompson BT, Ferguson ND, Caldwell E, Fan E, Camporota L, Slutsky AS. Acute respiratory distress syndrome: the Berlin Definition. JAMA. 2012;307:252633. [PubMed] [Google Scholar]

12. Chen N, Zhou M, Dong X, Qu J, Gong F, Han Y, Qiu Y, Wang J, Liu Y, Wei Y, Xia J, Yu T, Zhang X, Zhang L. Epidemiological and clinical characteristics of 99 cases of 2019 novel coronavirus pneumonia in Wuhan, China: a descriptive study. Lancet. 2020;395:507-13. [PubMed] [Google Scholar]

13. Kayina CA, Haritha D, Soni L, Behera S, Nair PR, Gouri M, Girish K, Deeparaj L, Maitra S, Anand RK, Ray BR, Baidya DK, Subramaniam R. Epidemiological \& clinical characteristics \& early outcome of COVID-19 patients in a tertiary care teaching hospital in India: A preliminary analysis. Indian J Med Res. 2020;152(1):100-4. [PubMed] [Google Scholar]

14. Mohan A, Tiwari P, Bhatnagar S, Patel A, Maurya A, Dar L, Pahuja S, Garg R, Gupta N, Sahoo B, Gupta R, Meena VP, Vig S, Pandit A, Mittal S, Madan K, Hadda V, Dwivedi T, Choudhary A, Brijwal M, Soneja M, Guleria R, Ratre B, Kumar B, Bhopale S, Panda S, Singh AR, Singh S, Wundavalli L. Clinico-demographic profile \& hospital outcomes of COVID-19 patients admitted at a tertiary care centre in north India. Indian J Med Res. 2020;152:61-9. [PubMed] [Google Scholar]

15. Guan WJ, Ni ZY, Hu Y, Liang WH, Ou CQ, He JX, Liu L, Shan H, Lei CL, Hui DS, Du B, Li LJ, Zeng G, Yuen KY, Chen RC, Tang CL, Wang T, Chen PY, Xiang J, Li SY, Wang JL, Liang ZJ, Peng YX, Wei L, Liu Y, Hu YH, Peng P, Wang JM, Liu JY, Chen Z, Li G, Zheng ZJ, Qiu SQ, Luo J, Ye CJ, Zhu SY, Zhong NS; China Medical Treatment Expert Group for Covid-19. Clinical characteristics of coronavirus disease 2019 in China. N Engl J Med. 2020;382:170820. [PubMed] [Google Scholar]

16. Grasselli G, Zangrillo A, Zanella A, Antonelli M, Cabrini L, Castelli A, Cereda D, Coluccello A, Foti G, Fumagalli R, Iotti G, Latronico N, Lorini L, Merler S, Natalini G, Piatti A, Ranieri MV, Scandroglio AM, Storti E, Cecconi M, Pesenti A; COVID-19 Lombardy ICU Network. Baseline 
characteristics and outcomes of 1591 patients infected with SARS-CoV-2 admitted to ICUs of the Lombardy region, Italy. JAMA. 2020;323:1574-81. [PubMed] [Google Scholar]

17. Vardavas $\mathrm{Cl}$, Nikitara K. COVID-19 and smoking: A systematic review of the evidence. Tob Induc Dis. 2020;18:20. [PubMed] [Google Scholar]

18. Patanavanich R, Glantz SA. Smoking is associated with COVID-19 progression: A meta-analysis. Nicotine Tob Res. 2020;22(9):1653-6. [PubMed] [Google Scholar]

19. Singer M, Deutschman CS, Seymour CW, Shankar-Hari M, Annane D, Bauer M, Bellomo R, Bernard GR, Chiche JD, Coopersmith CM, Hotchkiss RS, Levy MM, Marshall JC, Martin GS, Opal SM, Rubenfeld GD, van der Poll T, Vincent JL, Angus DC. The Third International Consensus Definitions for sepsis and septic shock (sepsis-3). JAMA. 2016 Feb 23;315(8):801-10. [PubMed] [Google Scholar]

20. Ferreira FL, Bota DP, Bross A, Melot C, Vincent JL. Serial evaluation of the SOFA score to predict outcome in critically ill patients. JAMA. 2001 Oct 10;286(14):17548. [PubMed] [Google Scholar]

21. Gao J, Zhong L, Wu M, Ji J, Liu Z, Wang C, Xie Q, Liu Z. Risk factors for mortality in critically ill patients with COVID-19: a multicenter retrospective case-control study. BMC Infect Dis. 2021;21:602. [PubMed] [Google Scholar]

22. Tan $C$, Huang $Y$, Shi $F$, Tan $K, M a ~ Q$, Chen $Y$, Jiang $X$, Li X. C-reactive protein correlates with computed tomographic findings and predicts severe COVID-19 early. J Med Virol. 2020 Jul;92(7):856-62. [PubMed] [Google Scholar] 